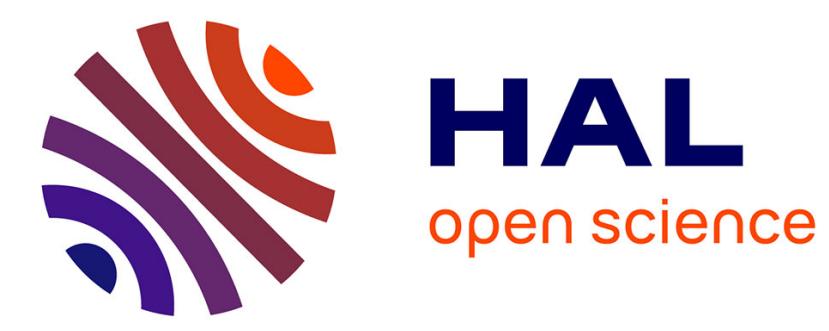

\title{
Vector control applied to a Langevin transducer
}

Sofiane Ghenna, Frédéric Giraud, Christophe Giraud-Audine, Michel Amberg,

Betty Lemaire-Semail

\section{To cite this version:}

Sofiane Ghenna, Frédéric Giraud, Christophe Giraud-Audine, Michel Amberg, Betty Lemaire-Semail. Vector control applied to a Langevin transducer. Conference on Power Electronics and Applications, Sep 2015, Genève, Switzerland. hal-01201885

\section{HAL Id: hal-01201885 https://inria.hal.science/hal-01201885}

Submitted on 18 Sep 2015

HAL is a multi-disciplinary open access archive for the deposit and dissemination of scientific research documents, whether they are published or not. The documents may come from teaching and research institutions in France or abroad, or from public or private research centers.
L'archive ouverte pluridisciplinaire HAL, est destinée au dépôt et à la diffusion de documents scientifiques de niveau recherche, publiés ou non, émanant des établissements d'enseignement et de recherche français ou étrangers, des laboratoires publics ou privés. 


\title{
Vector control applied to a Langevin transducer
}

\author{
Sofiane GHENNA ${ }^{1}$, Frédéric GIRAUD ${ }^{1}$, Christophe GIRAUD-AUDINE ${ }^{1,2}$, \\ Michel Amberg ${ }^{1}$ and Betty LEMAIRE-SEMAIL ${ }^{1}$ \\ ${ }^{1}$ Laboratoire d'electrotechnique et d'Eléctronique de Puissance, Université Lille1 \\ IRCICA, 50 avenue Halley, 59650 Villeneuve d'Ascq, France \\ 2 Arts et Métiers Paris-Tech \\ Centre de Lille, 8 bd Louis XIV, 59046 Lille, France \\ Phone: +33 (3) 62531632 \\ Email: sofiane.ghenna@ed.univ-lille1.fr \\ URL: http://12ep.univ-lille1.fr
}

\section{Acknowledgments}

This work has been carried out within the framework of the project StimTac of IRCICA (institut de recherche sur les composants logiciels et matériel pour la communication avancé), and the Project Mint of Inria.

\section{Keywords}

$<<$ Vector control $>>,<<$ modelling in a rotating frame $>>,<<$ Control of piezo-actuator $>>,<<$ Langevin ultrasonic transducer $>>,<<$ piezoelectricity $>>$.

\begin{abstract}
In this paper, the control of the vibration amplitude of a Langevin transducer is obtained simultaneously with the tracking of its resonant frequency. Vector control method is applied to achieve this. The result of this study is illustrated with experimental and simulation results.
\end{abstract}

\section{Introduction}

Currently the piezoelectric actuators take a prominent place in several fields (medicine, industry, aeronautics ....). Even if their role is important, their control is still an issue. Several studies have been done on the control of the piezoelectric actuators by changing the supply voltage amplitude, or frequency. The control described in [1] introduces two control methods to regulate the vibration amplitude using PI and PID controllers for machining application. However, this method does not address the problem of heating of the transducer, which shifts away the resonant frequency. And when the system is operated outside its resonance, it requires more voltage, thus leading to more dielectric losses. In forging processes, it is possible to control the vibration velocity in quasi-static state [2]. A Resonance Frequency Tracking System is introduced in [3] using digital circuits. By direct measurement of the phase difference between the applied voltage and the input current, the transducer is regulated at the resonant frequency. However the vibration amplitude is not controlled. In another method, the vibration motion is described in a rotating reference frame [4], and then the control of vibration amplitude can be deduced by a simple transfer function between the supply voltage and the vibration amplitude $[5,6,7]$. It should be noted that a tracking of the resonant frequency can be obtained by controlling the phase shift between the voltage and the wave amplitude.

In this paper, a rotating reference frame related to the vibration wave is introduced. The complex notation of different physical variables, and the decoupling according to two-axis allow us to obtain a double closed loop control. One closed loop is used to regulate the vibration amplitude, while the second is used for tracking of its resonance frequency. It acts directly on the amplitude of the imaginary part of the supply voltage as a classical electromagnetic machines [8]. Thanks to the vector control detailed here after. 


\section{LANGEVIN TYPE TRANSDUCER}

Langevin transducer was invented in 1922 [9] by Paul Langevin. Its current scope of use has significantly expanded due to its high power ratio and high energy conversion efficiency, especially for ultrasonic cleaning $[10,11]$, Cut or welding of thermoplastics $[12,13]$. It is non-magnetic material which it is useful in MRI (Magnetic resonance imaging) environment [14].

This resonator consists of two piezoelectric ceramics longitudinally polarized in opposite directions; the deformations are operated in the polarization direction, which adds the deformation of both of them. These ceramics are connected mechanically in series and electrically in parallel, sandwiched between two metal masses, generally aluminium, due to the large acoustic transmission properties and its ease of manufacturing. These masses are held by a pre-load bolt [15], which allows pre-loading the ceramics to prevent undesirable tensile stress; they are also used to calibrate the acoustic set at a predefined frequency.

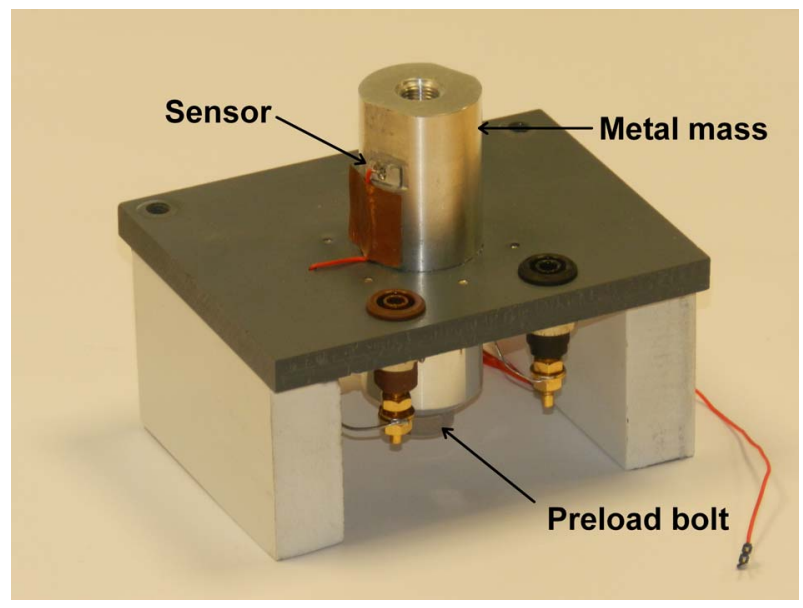

Figure 1: Example figure

\section{Electromechanical modelling}

To determine the equivalent electromechanical transducer scheme we will use the propagation of elastic waves through a metal [16] in general, then adding the equations of piezoelectricity to describe the piezoelectric ceramic stress [17].

The equivalent electromechanical circuit of the Langevin transducer, according to the Mason's model is given in Fig.2

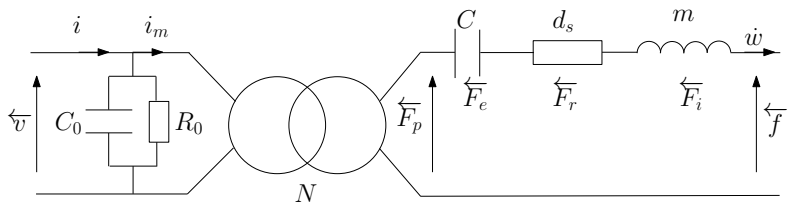

Figure 2: Electromechanical equivalent circuit of the piezoelectric actuator in vicinity of the resonance

The modelling of the electromechanical coupling uses an ideal transformer, with a transformer ratio $N$. The electrical variables are voltage $v$, current $i$, and $i_{m}$ is the motional current, $R_{0}$ and $C_{0}$ represent the dielectric loss and capacitance respectively. The mechanical variables are force $f$, and velocity $\dot{w}$.

The current flowing in the secondary is analogous to the velocity $\dot{w}$. The vibrating mass $m$ is equivalent to an inductance, a kinetic force or inertia related to the vibrating actuator and reflects the dynamic nature of the structure mass noted $F_{i}$, while the stiffness of the element takes the form of a capacitance $c$, resulting in an elastic force $F_{e}$. The dissipation phenomena of mechanical origin results in damping $d_{s}$ which is equivalent to a series resistance [5]. The corresponding forces are denoted $F_{r}$. The equation of motion about a vibration mode is given by:

$$
m \ddot{w}+d_{s} \dot{w}+c w=N V-F
$$

$w, \dot{w}$ and $\ddot{w}$ are displacement, velocity and acceleration respectively.

The equation Eq.1 describes the behavior of the vibration amplitude; it is a second order equation, forced by the voltage $V$ and the external forces $F$. This modeling will be established in a rotating reference frame in order to obtain the transfer functions needed for the control. 


\section{MODEL OF THE VIBRATION AMPLITUDE OF THE LANGEVIN TRANS- DUCER IN A ROTATING REFERENCE FRAME}

\section{Equation of vibration domain in a rotating reference frame}

In this paper, only harmonic vibrations are considered enabling the use of the complex notation in Eq.1 with $\underline{x}=\underline{X} e^{j \omega t}$, where $\underline{X}=X e^{j \alpha}, \alpha$ and $X$ are respectively the argument and the magnitude of $\underline{X}$ so much that:

$$
m \underline{\ddot{w}}+d_{s} \underline{\dot{w}}+c \underline{w}=N \underline{v}-\underline{f}
$$

The vibration amplitude, the supply voltage and the force generated by the actuator being respectively defined by:

$$
\begin{aligned}
& \underline{w}=\left(W_{d}+j W_{q}\right) e^{j \omega t} \\
& \underline{v}=\left(V_{d}+j V_{q}\right) e^{j \omega t} \\
& \underline{f}=\left(F_{d}+j F_{q}\right) e^{j \omega t}
\end{aligned}
$$

where $\omega$ is the angular frequency and $j=\sqrt{-1}$. This transformation can be illustrated as in figure 3 . In this figure the vectors $\underline{V}$ and $\underline{W}$ are rotating in the fixed frame, and fixed in the $(d, q)$ frame.

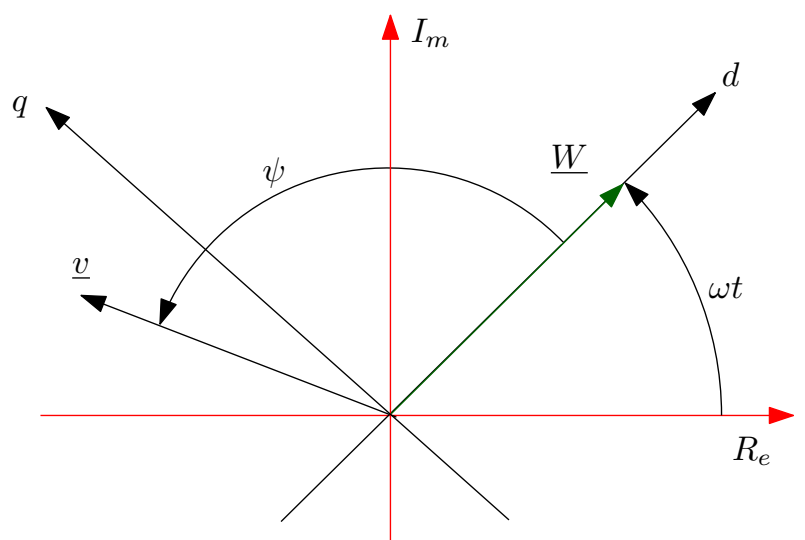

Figure 3: Representation of the vibration amplitude and the voltage in a rotating reference frame

By substituting the relation Eq.3 in Eq.2 with :

$$
\begin{aligned}
& \dot{\underline{w}}=\left[\left(\dot{W}_{d}+j \dot{W}_{q}\right)+j \omega\left(W_{d}+j W_{q}\right)\right] e^{j \omega t} \\
& \ddot{\underline{w}}=\left[\left(\ddot{W}_{d}+j \ddot{W}_{q}\right)+2 j \omega\left(\dot{W}_{d}+j \dot{W}_{q}\right)-\omega^{2}\left(W_{d}+j W_{q}\right)\right] e^{j \omega t}
\end{aligned}
$$

Along the $\mathrm{d}$ axis and q-axis yields:

$$
\begin{aligned}
& m \ddot{W}_{d}+d_{s} \dot{W}_{d}+\left(c-m \omega^{2}\right) W_{d}-\omega\left(2 m \dot{W}_{q}+d_{s} W_{q}\right)=N V_{d}-F_{d} \\
& m \ddot{W}_{q}+d_{s} \dot{W}_{q}+\left(c-m \omega^{2}\right) W_{q}+\omega\left(2 m \dot{W}_{d}+d_{s} W_{d}\right)=N V_{q}-F_{q}
\end{aligned}
$$

In this paper it is admitted that: $\ddot{W}_{d}<<2 \omega \dot{W}_{q}$ and $\dot{W}_{d}<<2 \omega W_{q}$ also $\ddot{W}_{q}<<2 \omega \dot{W}_{d}$ and $\dot{W}_{q}<<2 \omega$ $W_{d}$. Moreover, we consider no-load operations only and we set the vector $V$ on axis $q$, leading to $V_{d}=0$. These considerations lead to:

$$
\begin{aligned}
& \left(c-m \omega^{2}\right) W_{d}-\omega\left(2 m \dot{W}_{q}+d_{s} W_{q}\right)=0 \\
& \left(c-m \omega^{2}\right) W_{q}+\omega\left(2 m \dot{W}_{d}+d_{s} W_{d}\right)=N V_{q}
\end{aligned}
$$




\section{Identification of the transfer function near resonance}

At resonance, the coupling term $\left(c-m \omega^{2}\right) W_{d}$ is eliminated, and Eq. 8 yields $W_{q}=0$. Then Eq.9 becomes:

$$
\left(2 m \dot{W}_{d}+d_{s} \dot{W}_{d}\right)=N V_{q}
$$

The Laplace transformation gives rise to a first order equation:

$$
\frac{W_{d}}{V_{q}}=\frac{G}{1+\tau s}
$$

where

$$
\begin{gathered}
G=\frac{N}{d_{s} \omega} \\
\tau=\frac{2 m}{d_{s}}
\end{gathered}
$$

To determine the parameters of the transfer function, the actuator is unloaded (force end, $F=0$ ) placed at the resonance. This behaviour is confirmed by the experimental results of Fig.4, which are obtained at resonance $\left(\omega=\omega_{0}\right.$, with $\left.\omega_{0}=\sqrt{\frac{c}{m}}\right)$ and for a step variation of $V_{q}=5 \mathrm{~V}$ starting from different set points, to test the non-linearity of the transducer.

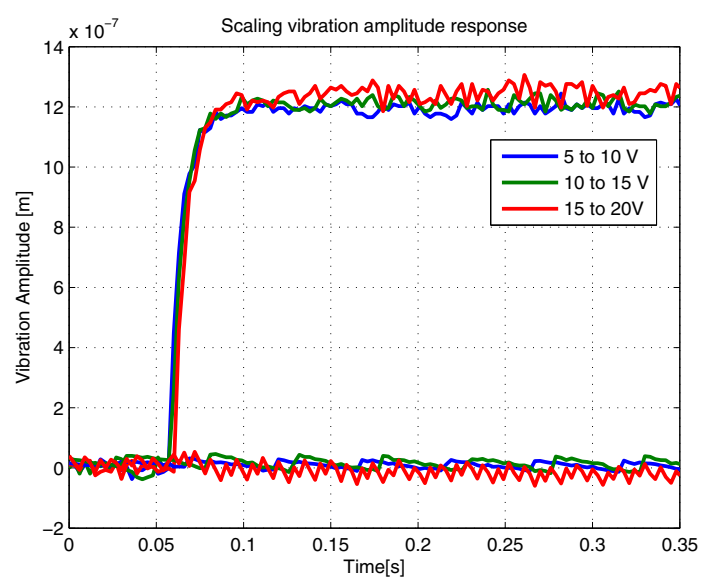

Figure 4: Scaling vibration amplitude response according to the rising edge $V_{q}$

The parameters of equation 11: gain $\mathrm{G}$ and time constant $\tau$ are deduced from the Fig.4 and are summarized in Tab.I.

Table I: Parameters of the actuator in the vicinity of resonance

\begin{tabular}{cccccc}
\hline$G[\mathrm{~nm} / \mathrm{V}]$ & $\tau[\mathrm{m} \mathrm{sec}]$ & $d_{s}[\mathrm{~N} / \mathrm{m} / \mathrm{sec}]$ & $m[\mathrm{~kg}]$ & $c[\mathrm{G} \mathrm{N} / \mathrm{m}]$ & $f[\mathrm{kHz}]$ \\
\hline 149.30 & 8.50 & 58.41 & 0.249 & 7.64 & 27.93 \\
\hline
\end{tabular}

These identified parameters will be used to calculate the regulators needed for the control of vibration amplitude and tracking of frequency, and use them in the simulation phase to compare the experimental curves with theoretical results.

\section{CONTROL OF VIBRATION'S AMPLITUDE AND FREQUENCY OF THE LANGEVIN TRANSDUCER}

To improve accuracy and robustness of the system, a closed loop control of $W_{d}$ is applied. In this paper, the voltage $V_{q}$ is used to control the vibration amplitude. In order to measure the vibration amplitude, 
a piezoelectric patch was glued in the metal mass of the actuator, to give the image of its vibrations; it is used as a sensor under the direct piezoelectric effect. A DSP, which is equipped with a digital analog converter measures $W_{d}, W_{q}$ and calculates the required value for $V_{q}$. It is also equipped with an analogdigital converter for processing the measured quantities (vibrations), and a Direct Digital Synthesizer (DDS) for generating a sinusoidal which is amplified using a linear amplifier. The description of the system is given in Fig.5, where, $R_{e}$ is the real part and PI (proportional integral).

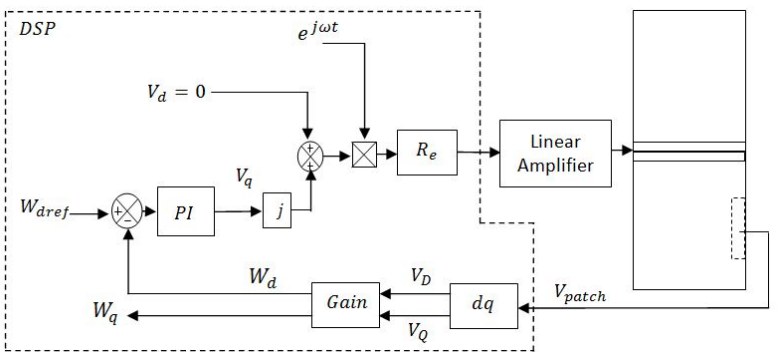

Figure 5: Block diagram of the control of the vibration amplitude of the Langevin transducer

The measured $W_{d}$ and $W_{q}$ are obtained in rotating frame through the voltage patch detailed here after.

\section{Reconstitution of the vibration amplitude in rotating frame}

The piezoelectric patch generates a sinusoidal voltage $\mathrm{V}$, accordingly to the direct piezoelectric effect. the real part of this voltage in a rotating reference frame is given by:

$$
V=V_{D} \cos (\omega t)-V_{Q} \sin (\omega t)
$$

In order to extract $V_{D}$ and $V_{Q}$ from the voltage $V_{\text {patch }}$, specific measurements are performed at $\omega t=n \frac{\pi}{2}$ where $n$ is an integer, as shown in Fig.6

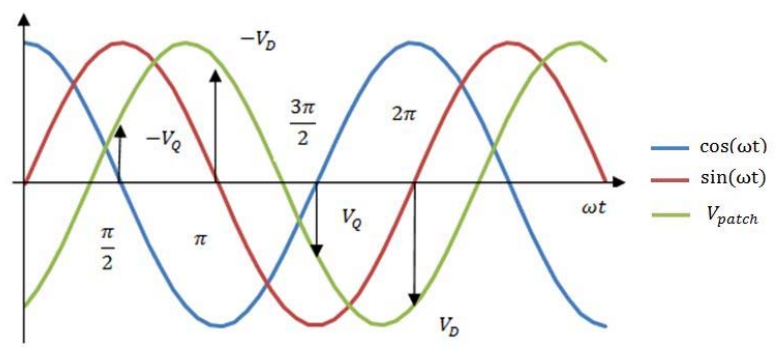

Figure 6: Reconstitution of the vibration amplitude

Through the identified gain, we determine the values of the vibration amplitude in rotating reference frame. Assuming a linear relationship between the vibration of transducer and the patch voltage, we can write:

$$
\begin{aligned}
& W_{d}=\text { Gain. } V_{D} \\
& W_{q}=\text { Gain. } V_{Q}
\end{aligned}
$$

To identify these relations, steps of voltage amplitude are applied to the transducer, and we measure the vibration amplitude and the patch voltage corresponding to these steps accordingly to Fig.7. From this result the vibration amplitude of the transducer depends linearly on the voltage amplitude of the piezo patch. Therefore the vibration amplitude in rotating frame can be calculated.

Comparing the experimental results and those from the electromechanical model, the experimental values follow well the model especially for the real part of the vibration amplitude as shown in Fig.8 These results are obtained at the resonance of the system, where $W_{q}=0$. However, outside the resonance $W_{q}$ is not null. This is why; the next section of the paper describes the tracking of the resonant frequency.

\section{Tracking the resonant frequency}

By applying Laplace transform on equation 8 leads to: 


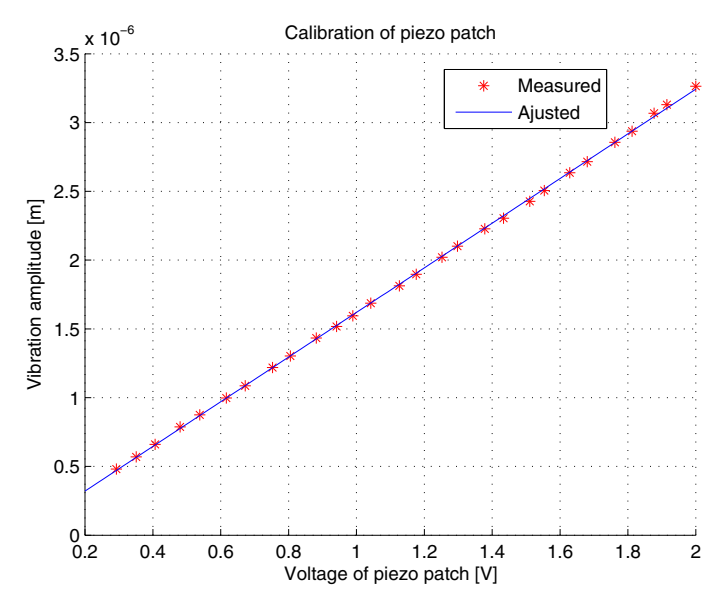

Figure 7: linear fitting of the vibration amplitude as a function of the patch voltage

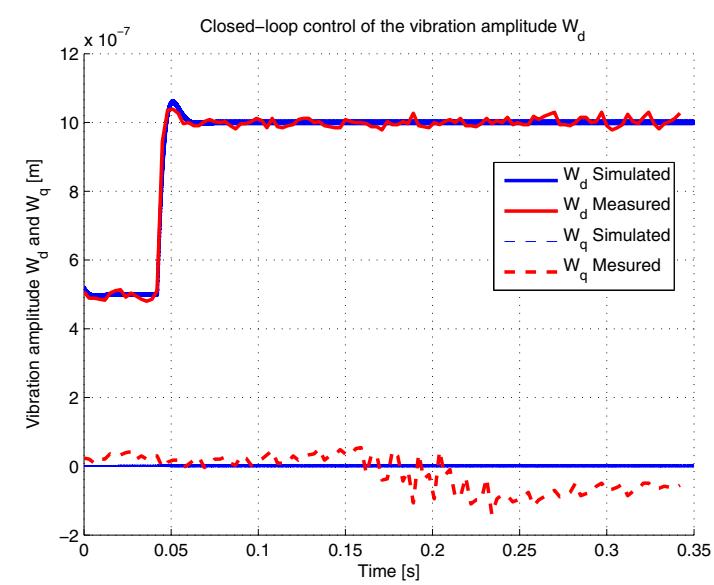

Figure 8: Control of the vibration amplitude at resonance

$$
\frac{W_{q}}{W_{d}}=\frac{\left(c-m \omega^{2}\right)}{\omega\left(2 m s+d_{s}\right)}
$$

The term $\left(c-m \omega^{2}\right)$ can be simplified, assuming small variations of the frequency around the resonant frequency. Indeed, with $\Delta \omega=\omega-\omega_{0}$ we have: $\left(c-m \omega^{2}\right) \approx-2 m \omega_{0} \Delta \omega$

The transfer function between the ratio $W_{q} / W_{d}$ as a function of the frequency shift is now given by:

$$
\frac{\frac{W_{d}}{W_{q}}}{\Delta f}=\frac{\frac{-4 \pi m}{d_{s}}}{\frac{2 m}{d_{s}} s+1}
$$

This transfer function is identified experimentally, by exciting the transducer with frequency steps. The variation of the ratio $W_{q} / W_{d}$ is measured under static conditions as Fig.9

This ratio at resonance is zero; when the resonance frequency is changing due to the temperature rise. For example the curve in Fig.9 translates laterally. In static conditions the characteristic equation of this straight line is given by: $\frac{W_{d}}{W_{q}}=2 \pi \tau \Delta f$. The time constant is estimated to be $\tau$

A closed loop control is then achieved, based on this modeling. As described in Fig.10, it consists in calculating $W_{q} / W_{d}$. Then an integral corrector is used to determine the frequency to apply to the system. Naturally, this frequency will converge toward the value which annihilates $W_{q} / W_{d}$, which is the resonant frequency. 


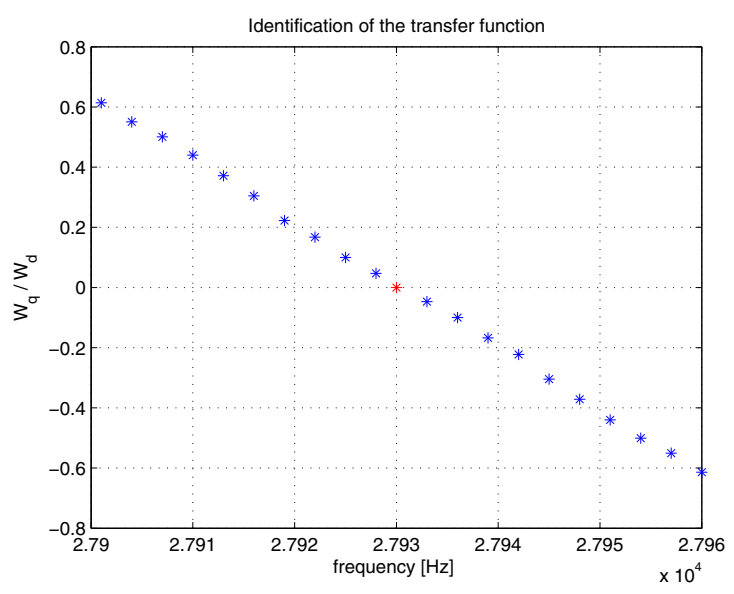

Figure 9: Variation of the ratio $W_{q} / W_{d}$

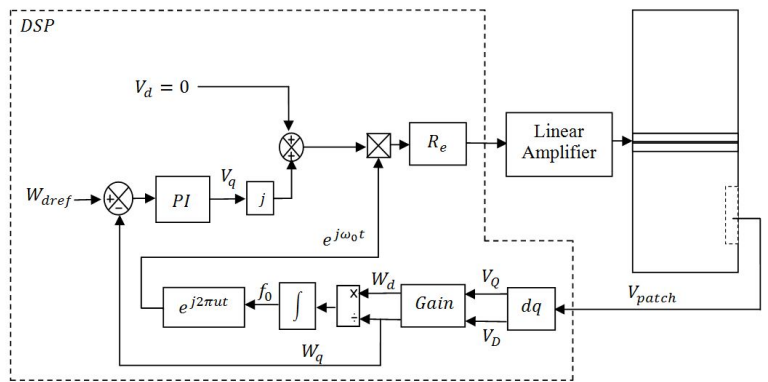

Figure 10: Block diagram control of the vibration amplitude and the resonant frequency

\section{Practical results of frequency tracking combined with the control of the vibration ampli- tude}

During this try, the system operates about $20 \mathrm{~Hz}$ away of its resonant frequency, which is estimated at $27925 \mathrm{~Hz}$. This simulate the influence of the external factors such as the temperature, which shift away the resonant frequency. The vibration amplitude is controlled to $2 \mu \mathrm{m}$. Between 0 and $20 \mathrm{~m} \mathrm{sec}$ the regulation of the amplitude is activated alone; hence, the imaginary component $W_{q}$ is present, because the system doesn't operate at its resonant frequency. Indeed coupling terms are not null in Eq.8. Fig.11 presents the evolution of the evolution of the vibration amplitude.

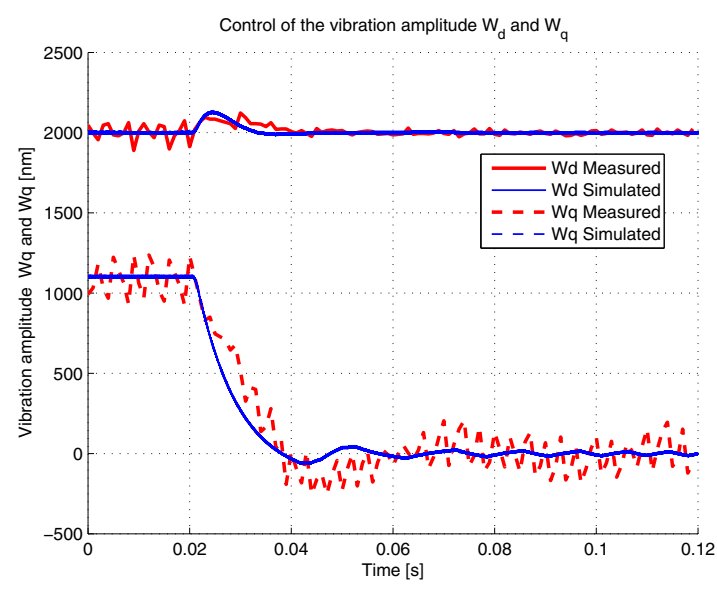

Figure 11: Comparison between measured and simulated vibration amplitude in a rotating frame

At $t=20 \mathrm{msec}$, the frequency control is activated in addition to the control of amplitude. Integral action converges to the resonant frequency: $W_{q}$ decreases to 0 , while $W_{d}$ is kept constant.

Fig. 12 depicts the evolution of $V_{q}$ as a function of time. It is also equal to the amplitude of the supply 


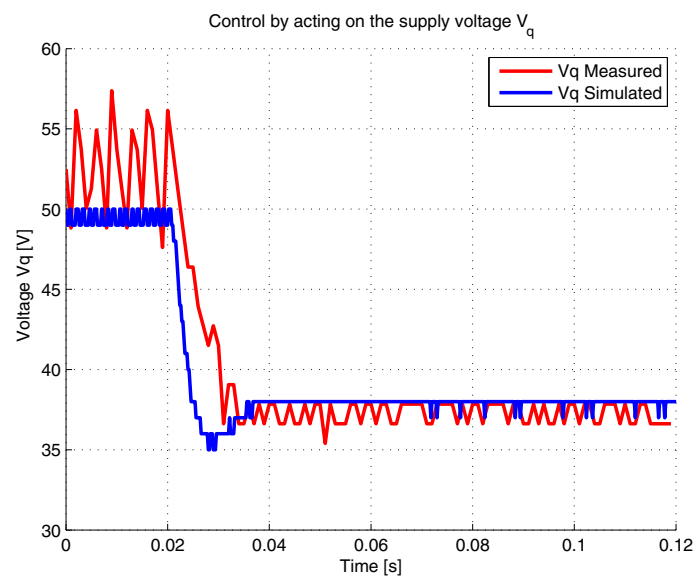

Figure 12: Comparison between measured and simulated voltage $V_{q}$

voltage. It shows that it has been decreased by $30 \%$ when operating at resonance, thus decreasing the dielectric losses. Fig.13 shows the evolution of the frequency during the test. Results from the model

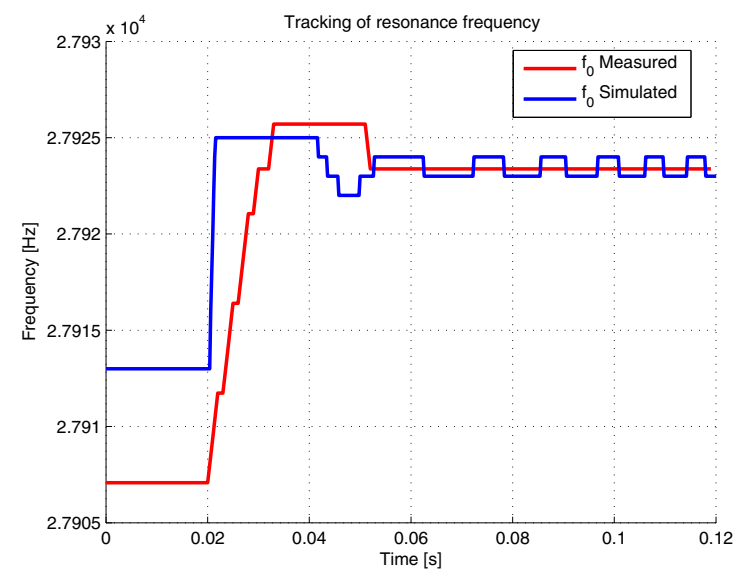

Figure 13: Results after switching the frequency tracking

are close to the experimental results. They validate the modelling, and confirm that two simultaneous control loop with approximately the same response time can be used to control the vibration amplitude and to track the resonant frequency.

\section{CONCLUSION}

A Langevin transducer model is described in a rotating reference frame, related to the vibration wave, based on the model of the equivalent electric circuit near resonance. A control of the vibration amplitude is then established with numerical simulations, an experimental validation is assessed. A tacking of the resonance frequency is proposed in order to ensure the performances of the actuator independently of the external factors.

\section{ACKNOWLEDGMENT}

This work has been carried out within the framework of the project StimTac of IRCICA (institut dde recherche sur les composants logiciels et matériel pour la communication avancé), and the Project Mint of Inria. 


\section{References}

[1] Saleem, M. Salah, N. Ahmad, and V. Silberschmidt, "Control of ultrasonic transducers for machining applications," in 2013 9th International Symposium on Mechatronics and its Applications (ISMA), 2013, pp. $1-5$.

[2] C. Giraud-Audine, T. H. Nguyen, M. Amberg, B. Lemaire-Semail, G. Abba, and R. Bigot, "Control of a multi-degree of freedom worktool for vibrations assisted forging," in 2014 IEEE/ASME International Conference on Advanced Intelligent Mechatronics (AIM), 2014, pp. 812817.

[3] M. Takasaki, Y. Maruyama, and T. Mizuno, "Resonance Frequency Tracing System for Langevin Type Ultrasonic Transducers," in Mechatronic Systems Simulation Modeling and Control, A. M. D. Di Paola and G. Cicirelli, Eds. InTech, 2010.

[4] F. Giraud, B. Semail, and J.-T. Audren, "Analysis and phase control of a piezoelectric traveling-wave ultrasonic motor for haptic stick application," IEEE Transactions on Industry Applications, vol. 40, no. 6, pp. 15411549, Nov. 2004.

[5] F. Pigache, F. Giraud and B. Lemaire-Semail: Modelling and identification of a planar standing wave ultrasonic motor. Identification of a planar actuator, Eur. Phys. J. Appl. Phys. 34, 55-65 (2006).

[6] F. Giraud, M. Amberg, and B. Lemaire-Semail, "Design and control of a haptic knob," Sensors and Actuators A: Physical, vol. 196, pp. 7885, Jul. 2013

[7] W. Ben Messaoud, F. Giraud, M. Amberg, M.-A. Bueno, B. Lemaire-Semail, "Closed-Loop Control for Squeeze Film Effect in Tactile Stimulator," International Conference and exhibition on new actuators and drives (Actuator 2014).

[8] T. Ohtani, N. Takada, and K. Tanaka, "Vector control of induction motor without shaft encoder," IEEE Transactions on Industry Applications, vol. 28, no. 1, pp. 157164, Jan. 1992.

[9] T. Sashida and T. Kenjo, An Introduction to Ultrasonic Motors. Clarendon Press, 1993.

[10] L. Shuyu, "Sandwiched piezoelectric ultrasonic transducers of longitudinal-torsional compound vibrational modes," IEEE Transactions on Ultrasonics, Ferroelectrics, and Frequency Control, vol. 44, no. 6, pp. 11891197, Nov. 1997.

[11] E. Moreno, P. Acevedo, M. Fuentes, A. Sotomayor, L. Borroto, M. E. Villafuerte, and L. Leija, ”Design and construction of a bolt-clamped Langevin transducer," in 2005 2nd International Conference on Electrical and Electronics Engineering, 2005, pp. 393-395

[12] P. Vasiljev, D. Mazeika, and S. Borodinas, "Minimizing heat generation in a piezoelectric Langevin transducer," in Ultrasonics Symposium (IUS), 2012 IEEE International, 2012, pp. 2714-2717.

[13] A. Iula, "Design and Experimental Characterization of a Multifrequency Flexural Ultrasonic Actuator," IEEE Transactions on Ultrasonics, Ferroelectrics and Frequency Control, vol. 56, no. 8, pp. 1725-1730, 2009.

[14] K. Hynynen, N. McDannold, N. Vykhodtseva, and F. A. Jolesz, ”Noninvasive MR Imaging-guided Focal Opening of the Blood-Brain Barrier in Rabbits," Radiology, vol. 220, no. 3, pp. 640-646, Sep. 2001.

[15] B. Fu, T. Li, and T. Hemsel, "Multiobjective Optimal Design of Symmetrical Langevin Transducers," in International Joint Conference on Computational Sciences and Optimization, 2009. CSO 2009, 2009, vol. 2, pp. 1017-1020.

[16] J. L. Rose, Ultrasonic Waves in Solid Media.Cambridge University Press, 2004.

[17] J. Yong and J.-F. Rouchon,"Resonant piezoelectric force sensor using two bending differential modes," in 2011 IEEE International Symposium on Industrial Electronics (ISIE), 2011, pp. 1307-1312. 